\title{
Accessing Space: ISS Integration for a US Payload on the JEM-EF
}

\author{
Perry G. Ballard \\ Chief Engineer, DOD Payloads Office \\ Johnson Space Center \\ Mail Code: JSC/WR1 \\ 2101 NASA Parkway \\ Houston, TX \\ 713-410-5835 \\ Perry.g.ballard@nasa.gov
}

\begin{abstract}
The Department of Defense (DoD) Space Test Program (STP) has launched the Hyperspectral Imager for the Coastal Ocean (HICO) \& Remote Atmospheric \& Ionospheric Detection System (RAIDS) Experiment Payload (HREP) to the International Space Station's Japanese Experiment Module - Exposed Facility (JEM-EF).

${ }^{12}$ HREP was launched as a NASA payload onboard the JAXA HTV/H-IIB first flight from the Tanegashima Space Center (TNSC) in September 2009. HREP was installed on the ISS and has been functioning since that time. Because STP is the organization responsible for providing launch services for all of DoD's R\&D space experiments and has used the International Space Station extensively in the past for its experiments, a concerted effort began seeking means to continue use of the ISS once the Shuttle retires, HREP launching on the JAXA HTV is one of these efforts.
\end{abstract}

This paper presents both the development of HREP and its ISS integration as well as providing insights into issues related to taking a US payload to JAXA for launch. Specifically the paper deals with practical aspects not only of integration but also of living and working in Tanegashima.

\section{TABLE OF CONTENTS}

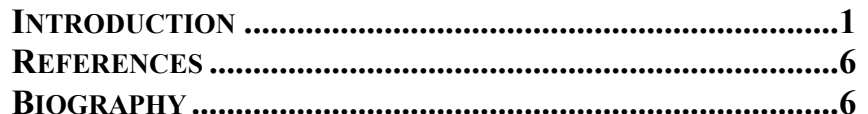

\section{INTRODUCTION}

The Department of Defense Space Test Program (STP), managed by the Air Force Space and Missile Systems Center, Space Development and Test Wing at Kirtland AFB, New Mexico serves the military research and development community by providing unique and valuable spaceflight opportunities for advanced Department of Defense (DOD)-sponsored experiments that do not have their own means for spaceflight. In addition to providing spaceflight opportunities, STP manages and funds the spacecraft and launch vehicle integration, and one year of

\footnotetext{
${ }^{1}$ U.S. Government work not protected by U.S. copyright

${ }^{2}$ IEEEAC paper\#1064, Version 1, Updated 2011:01:22
}

payload operations. The objective of the Space Test Program is to implement missions to fly the experiments on the DOD Space Test Program priority list. DOD experiments normally originate in DOD laboratories or in research institutions. To obtain spaceflight for an experiment, the sponsoring agency submits a request for spaceflight through channels to the Air Force headquarters. The Air Force serves as DOD's Executive Agent to execute the Space Test Program. Each year, headquarters convenes a tri-Service board known as the Space Experiments Review Board (SERB) to review and prioritize all submissions. The prioritized list of experiments is then forwarded to the Space Test Program Office [delete: of the Air Force Space Command] for planning and execution of the flight program.

Once an experiment makes the priority list, STP pursues one of three methods used to launch the experiment into space. First, STP funds, develops, integrates, and launches its own sophisticated free-flying spacecraft for experiments with unique orbital requirements. Second, STP launches experiments as a secondary payload (also known as a "piggyback") onboard the spacecraft of other DOD, NASA, and foreign space agencies. Finally, STP gains spaceflight for many experiments by manifesting them on the Space Shuttle and International Space Station. Often, technology proven through STP experiments evolves into a new realm of capabilities. The knowledge gained from STP experiments on radiation belts, satellite charging, and rubidium atomic clocks greatly contributed to the creation of the Navigation System using Timing and Ranging/Global Positioning System (NAVSTAR/GPS). NAVSTAR/GPS provides precise navigation information to a variety of military and civilian users. Since its inception in 1966, STP has flown 494 experiments on 206 missions (as of Oct 2010), directly benefiting scientific research and many operational satellite programs.

HREP combines two DOD experiment sensors into one payload, HICO (Hyperspectral Imager for the Coastal Ocean) and RAIDS (Remote Atmospheric and Ionospheric Detection System). The designation HREP comes from the JAXA tendency to add "experiment payload" at the end of their experiment names - hence HICO-RAIDS became "HREP". HICO is the first Maritime Hyperspectral Imager 
from space and RAIDS will provide the most comprehensive survey of the ionosphere and thermosphere in over 20 years. HREP was launched to the ISS as a part of the inaugural flight of the H-IIB Transfer Vehicle (HTV1) mission and installed on the Japanese Experiment Module - Exposed Facility (JEM-EF), using a combination of the ISS and JEM robotics systems (EVR). The International Space Station (ISS) provides power and command and data handling through the NASA Payload Operations and Integration Center (POIC) at the Marshall Space Flight Center (MSFC) utilizing the Telescience Resource Kit (TReK). TReK provides data and commanding directly to the Principal Investigators site with backup capability at the STP payload operations control center (POCC) at the Johnson Space Center. HREP requires no ISS crew interaction for completion of its science objectives.

Working with the NASA Space Station Payloads Office and the Japanese Aerospace Exploration Agency (JAXA), STP proposed flying two DOD experiments on the Japanese Experiment Module-Exposed Facility (JEM-EF). In early 2007, STP explored alternatives and possible experiments that would work on the JEM-EF and held discussions with both JAXA and the science teams. Initial meetings with JAXA were positive and it was agreed that the project should move forward. Our initial meetings were completed in February 2007 and we held a project kickoff meeting at the end of Mar 2007, after all the parties (STP, NASA, Scientists, JAXA) were convinced it was a feasible plan. The HREP Payload Integration Agreement, the NASA requirements document for the payload, was drafted by the middle of April 2007 and the first of HREPs three interface control documents (ICDs) were drafted. The three HREP ICDs were 1) HREP to ISS (software or command/control), 2) HREP to JEM-EF, 3) HREP to HTV. Each ICD had requirements and verifications that had to be reconciled and tracked. The HREP team held a Preliminary Design Review in July of 2007, with each of the primary experiments (HICO and RAIDS) holding separate reviews previously over the summer. The first safety review for HREP was held in August of 2007 as a Phase 0/1. The safety process for HREP was complicated by the fact that JAXA and NASA had not yet come to a mutual agreement on who would be in charge of what part of the process (ISS, Launch Vehicle, Service Vehicle). Resolving this issue, so that all of the safety aspects of the entire HREP mission could be addressed adequately and still satisfy both organizations was a bit of a coordination challenge. But, once the "leader/follower" roles were defined for each phase of HREPs "lifetime" was agreed upon the process worked fairly smoothly. The HREP Critical Design Review was held in January of 2008, with delivery of NASA provided equipment occurring in March 2008 to be installed into the payload structure.

NASA provided items for the HREP payload included the robotics grapple fixture, the payload interface to the JEM-EF, and several thermistors used by JAXA for monitoring temperatures. The robotics fixture is a standard item for NASA to provide, the other items were provided by JAXA via NASA. HREP was shipped to the JAXA Tanegashima Space Center (TNSC) by NASA in April of 2009, tested by the HREP team and delivered to JAXA for installation into the HTV in May. The HTV was launched on 10 September 2009 and arrived at the ISS on the 17th. HREP operations began with turn on and checkout on the 24 th of September, with full science operations starting on

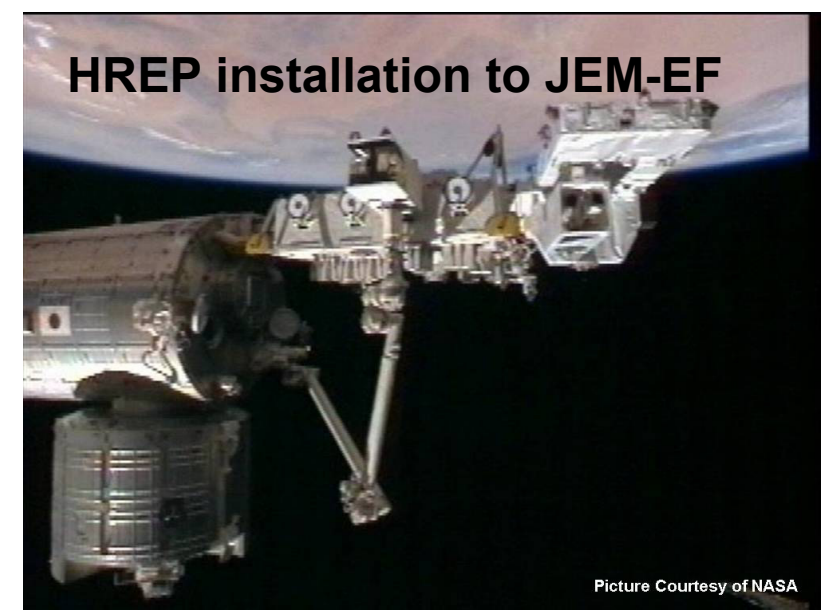

October 30th.

STP chose this method of spaceflight for a couple of reasons. First, it was a way to get long time operations for a couple of science experiments that needed it; both HICO and RAIDS required a host spacecraft that was substantial by Space Test Program standards. The ISS could provide power, attitude control, and communications with relative ease that met both experiment's requirements. Second, it was the best fit economically; NASA had an allocation on the first HTV launch but no payloads were ready to fly. STP could put HREP together in the time required which both took advantage of the HTV-1 slot and provided STP with an affordable mission for 2 large experiments.

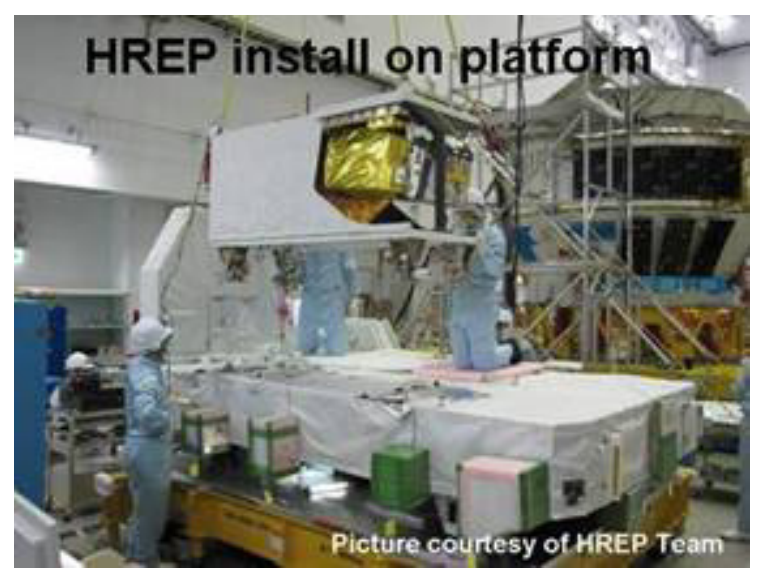

With the cultural barriers of Japanese and American language, differences in organizational cultures between 
STP and JAXA, as well as assumptions, the importance of regular contact on all aspects of any joint project cannot be overestimated. For HREP we held meetings with the Japanese at milestones only. Teleconferences were reserved for resolving specific issues. From the previous sentences it is implied that this did not work well. Because our interactions were infrequent, understanding was difficult to build. On the US side we did not comprehend the driving forces behind some Japanese requirements until late in the process. For example, the Japanese procedure was to analyze every possibility in design, thus ensuring that any question could be answered. On the HREP team we had only a fixed amount of time and money for analysis. So of course we needed to know the minimum required to reach flight. Our going in concept was to bound the requirements as much a possible, analyze to the boundaries and be done. Since the two sides (JAXA and STP) had very different assumptions - we had confusion. It took time to work through the confusion, so you want to avoid that on future projects. Plan to talk to JAXA monthly and have face to face meetings on issues quarterly. You may not need all these, but planning for them up front creates the expectation of interaction - which helps. A good point to remember is that JAXA, at least in the HREP time period, did not have a standing army of engineers. People were brought in to handle specific tasks and for meetings as required. For HREP it meant that to speak to a specific engineer may require a week or more of scheduling. This fact of life caused us some consternation at first, but it was easily compensated for.

When working with multiple interface control documents (ICDs) it is especially important to ensure that they not contradict each other. Also, ensure that your ICDs are the only applicable requirements for your project. Other documents may be referenced, but only what is specifically called out in the ICD is what is required. As these requirements drive your design and documentation - make them right! Also, defend yourself from requirements creep - it will drive you crazy and destroy your schedule.

Be aware that each requirement you have in your ICDs must be verified in some way. Key to that is some kind of "verification plan", even if it is just a table in the back of each ICD. For your verifications it is really important to give each one a number, understand what it will take to complete it (close it in the vernacular), who must agree that it has been completed correctly, and when. You must agree on these things with JAXA, not NASA, and definitely not among yourselves. If you have to make several trips to Japan to do "line by line" reviews of your ICDs, do it. It will pay off when you get ready for launch. For HREP, since we had JAXA bolting on some critical interface hardware, we actually shipped our first payload structure base to Japan to allow JAXA to do fit checks. This drove some procedural changes, as well as boosting everyone's confidence that HREP would be mounted successfully. The same thing goes for your software ICD with NASA; this is with the Payload Operations Integration Center at Marshall, not at Johnson. We actually took HREP to Marshall Spaceflight Center to do electrical testing with the ISS simulators they have there - it was very useful for working out some of our communications details and closing verifications. One last foot stomp on verifications it is absolutely essential to agree to all of these before testing starts. You only want to do most tests once, so understanding what you need to get out of each test is really important!

Since HREP would be shipped to Japan from the United States, NASA was required to obtain an export license for the payload on the ground support equipment. It is very important to understand the export classification of the shipment. HREP contained mostly commercial electronics, but the star tracker drove us to get an export license from the US Department of State. Work the licensing as early as you can, the details of the process can really take some time to work out. A few comments about shipping; have a detailed inventory and keep it current! For shipping purposes as well as export control, HREP had three types of equipment; Flight Hardware (the HREP experiment, Controlled Ground Support Equipment (GSE that would come back to the US), and Uncontrolled Ground Support Equipment (GSE that may or may not come back, depending on if it got used up). Wipes and clean room booties are examples of Uncontrolled GSE, while a calibrated torque wrench would be controlled GSE. Each type of equipment had its own set of export paperwork (classification worksheet and pro-forma invoice).

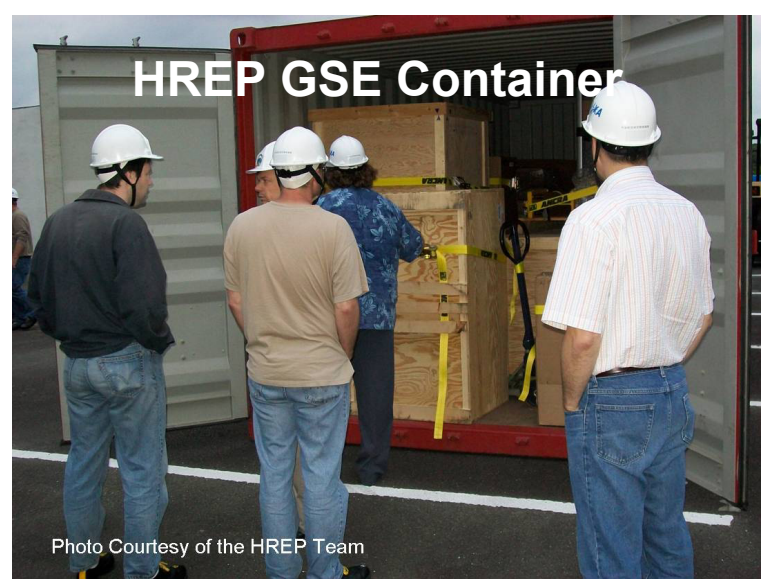

To make things easier for ourselves and the shipping folks, the HREP team actually took pictures of each item with its number on the inventory so they could easily be identified. When you have fourteen different types of tape this can be important. Keep track of everything, especially if you have multiple boxes. You may need to be able to direct them as to which box something is in (in case an inspector spot 
checks the shipment.) We had a cargo container full of stuff and being able to tell them there was a binder full of pictures just inside the door was very helpful according to our shipper. The language barrier caused a little confusion, but if you can say "it's the roll of tape in picture number 23, container 8", then they usually know what you are talking about. It is important to keep track of what you use if you are going to send it back to the US. It will change your inventory, etc... In a related topic, if you buy anything in Japan, it must go back on a separate shipment than the original because of Japanese export laws. So that means you need more paperwork; plan well - you have to live with it!

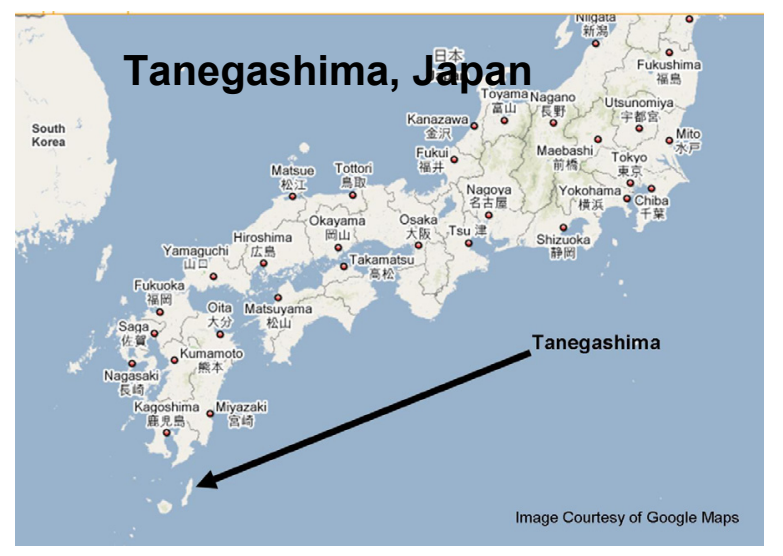

The Japanese launch from the Tanegashima Space Center (TNSC), which is located south of the main islands in the Kagoshima Prefecture. Tanegashima is the island where western firearms were first introduced to Japan by the Portuguese. It is still pretty famous for making scissors and knives.

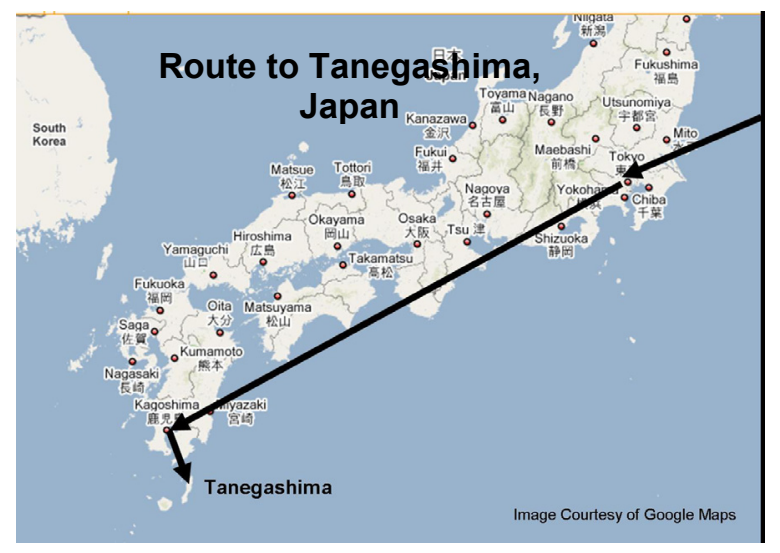

The Tanegashima Space Center (TNSC) is located on the southern end of Tanegashima. Just a quick language note - "shima" is the Japanese suffix for island, so it is really Tanegashima is literally "Tanega Island". In order to get there you can take a couple of routes, but all eventually go through the Kagoshima Airport to get to Tanegashima. The HREP team usually flew into Tokyo's Narita Airport, spent the night and then flew from Haneda down to Kagoshima to make a connection to Tanegashima. From the Tanegashima Airport you rent a car and drive to the town of Minimatane. Our team stayed at the Sun Pearl Hotel and drove to the space center each day.

The TNSC badging is similar to most of the western space centers. You get a photo badge that is electronically used in badge readers. There are also security guards at most of the outer fence lines, but we usually never had any issues getting in and out. The normal work day at TNSC is about 8 am until $5 \mathrm{pm}$, but since they have a lot going on they are pretty flexible if you want to work off normal hours. They are pretty strict about keeping weekends clear, so if you need to work on the weekends make sure you pre-coordinate the schedule. As a matter of fact, it is a really good idea to have at least a "day by day" plan that you have talked to JAXA about. The HREP team was in Tanegashima during Japan's "Golden Week" of four national holidays (Showa Day, Constitution Day, Greenery Day, Boys Festival), and we had to plan around that as well. Most of the impact was when the TNSC Cafeteria would be open (so we had to bring our own lunches). In your predeparture meetings ensure you go over what is expected to happen each day, as a lot of people on the JAXA side will be interested.

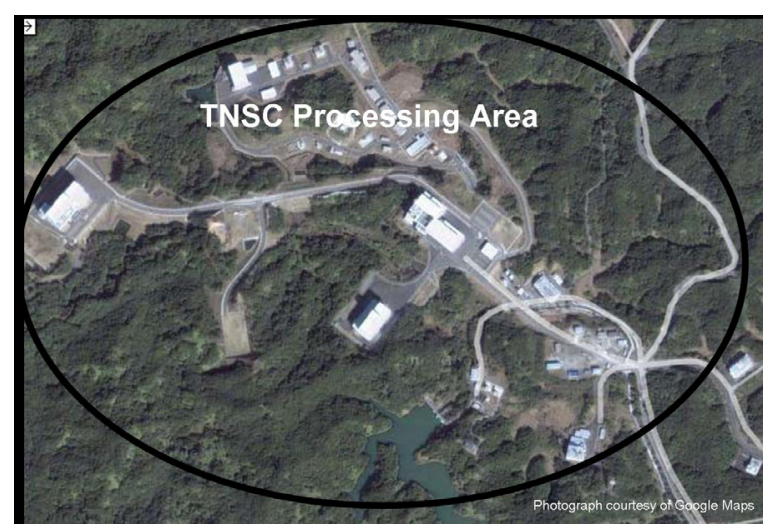

A key point to understand is that the entire area inside the fence at TNSC (see the circle in the picture above) is considered by JAXA an explosives safety area. So, they require "static resistant clothing" and safety shoes to be worn by everyone. This means you basically need to wear some kind of uniform while working at both the spacecraft 
processing areas (a little leeway) and in the integrated facility (no leeway). We didn't understand this when we first got to Tanegashima and had to express order safety clothing for our team. We also had to borrow safety shoes all of this could have been avoided if the site requirements had been better understood prior to us getting there. This was a mutual misunderstanding, JAXA thought their document was clear, and we didn't read it the same way. We had this misunderstanding even after making a trip to TNSC, so just be extra specific and ask lots of questions.

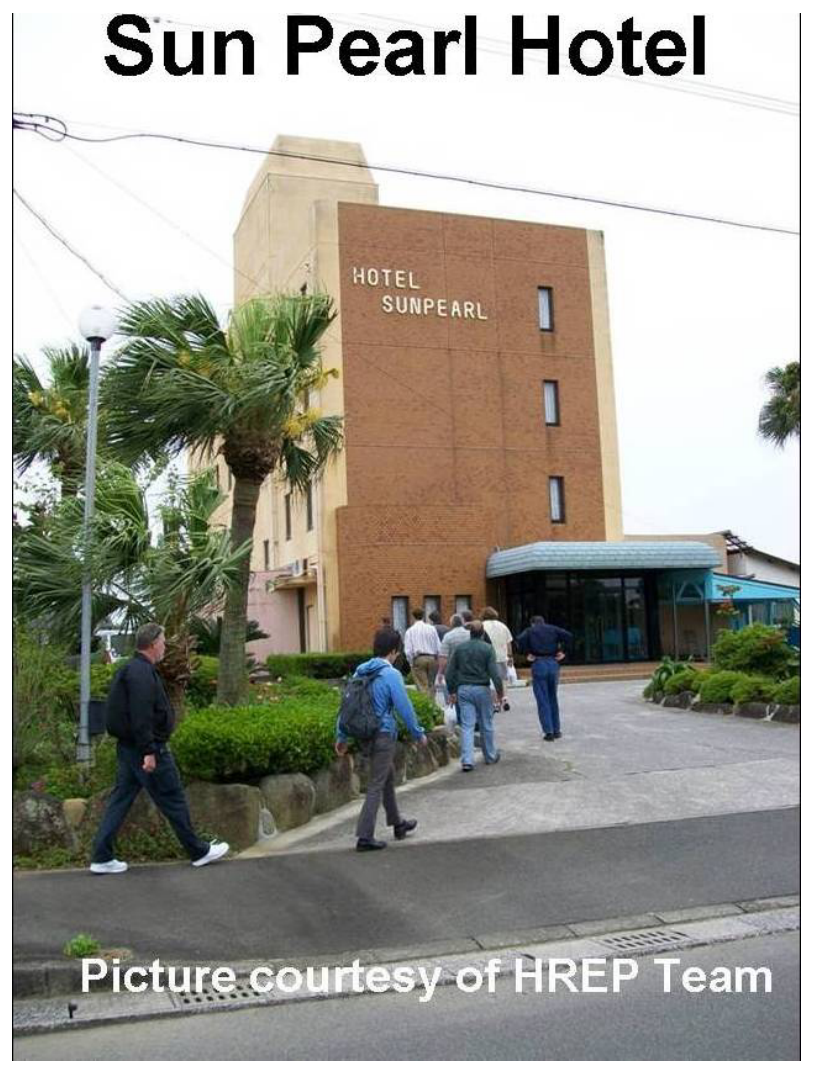

We stayed at the hotel SunPearl in Minimatane, most of the JAXA people stay there also. The hotel offers a western style breakfast and dinner service (Japanese style) as well as laundry. The hotel will even make box lunches for you on request. We did this on several occasions and it made a very enjoyable picnic.

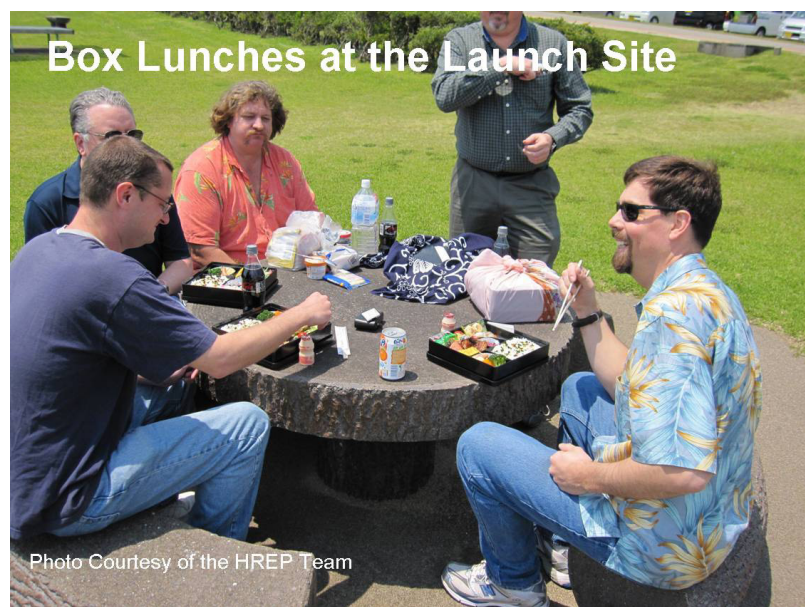

Getting around Minimatane was pretty simple, once you found the map (see below)

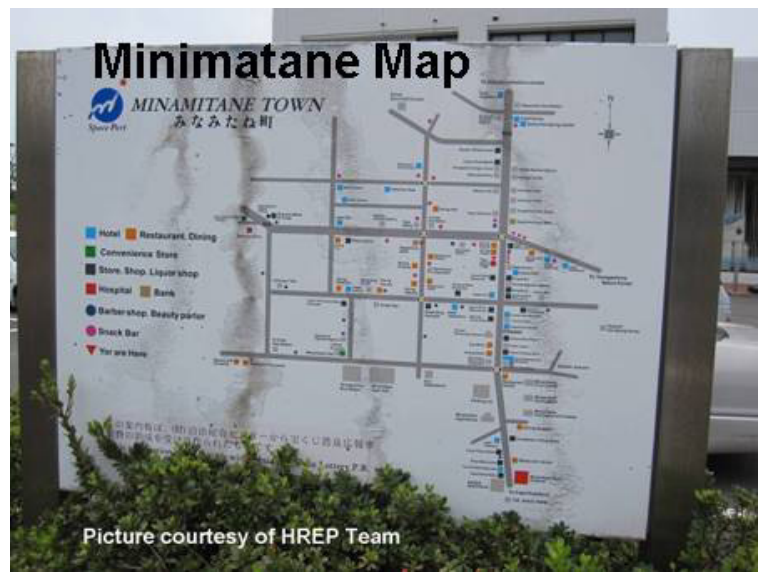

There are several of these English maps around town; we just took a picture and printed it out. Our team also put together an interactive map in power point so we could show what each place looked like. Overall, the people and culture were very welcoming. Local restaurants were always happy to see us and even though our team spoke no Japanese, we always seemed to communicate. We even had locals who spoke some English volunteer to help us at restaurants. We even found a taco restaurant to celebrate Cinco de Mayo at on the island, and the owners welcomed us (see picture below). 


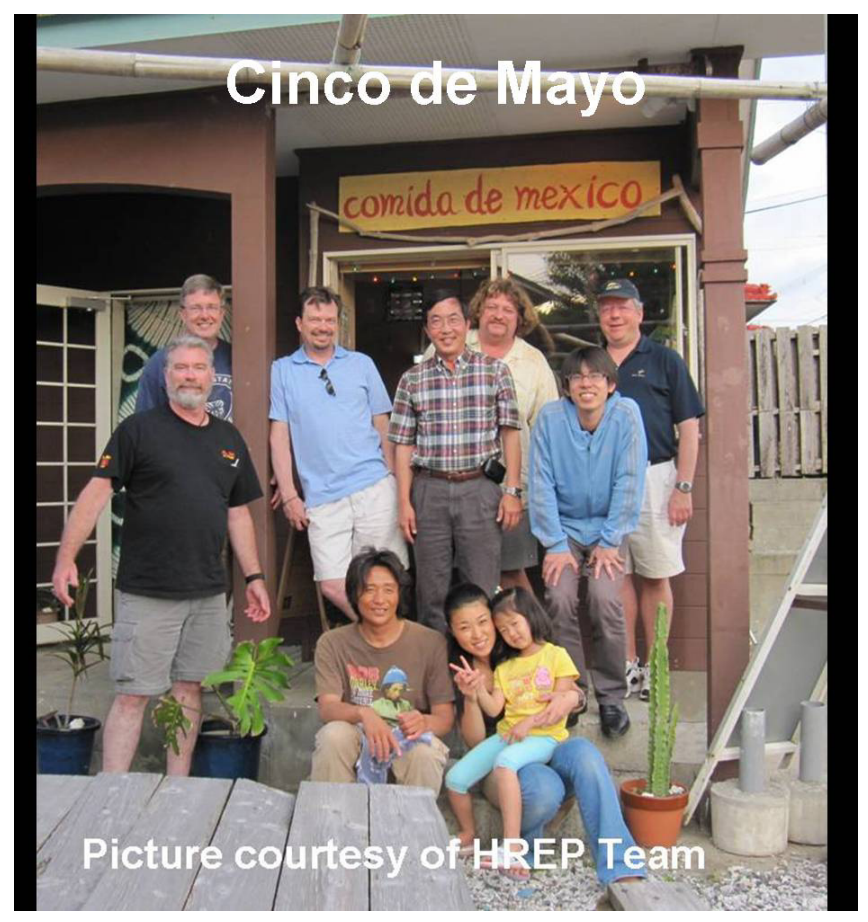

Overall, the HREP teams experience in Tanegashima was very rewarding. All of us on the HREP team would launch from TNSC again if the opportunity arose.

\section{References}

\author{
6/1/201 NRL PRESS RELEASE: \\ HTTPS://WWW.NRL.NAVY.MIL/MEDIA/NEWS- \\ RELEASES/65-10R/
}

\section{BIOGRAPHY}

Perry G. Ballard is the Chief Engineer, DOD Manned Spaceflight Payloads Office, Space and Missile Systems Center, Operating Location Y, Johnson Space Center (Houston, TX). On behalf of the Director, Perry provides senior engineering oversight of all DOD and STP Human Spaceflight projects. Perry provides technical assistance to Payload Integration in the areas of Systems Engineering, Information Protection, and Export Control. He represents the DOD Space Test Program to the NASA Export Control Office as the Export Control Representative for Shuttle and
International Space Station payloads. Mr. Ballard represents OL-Y and DOD Space Test Program to interests to outside organizations in support of mission accomplishment. Perry is also the Mission Manager for several payloads in the launch process. During his 22 year military career Perry was the Acting Program Director for the DOD Space Test Program - where he lead a team that participated in the first space launch from Kodiak, Alaska, was assigned as the Collection Systems Program Manager, Director of Intelligence Operations of the Defense Intelligence Agency and served as a Chief of Space Shuttle and Atlas Payloads at Cape Canaveral, Florida.

Mr. Ballard, a Florida native, received his commission from Officer Training School in 1980 after earning a Bachelor's Degree from the Missouri Institute of Technology. Perry also holds a master's degree from the University of West Florida. He has been working with space systems for over 15 years. He was responsible for payloads on the space shuttle return to flight from Challenger mission as well as payloads on over forty launches using nine different launch systems. Mr. Ballard's background includes flight-testing, maintenance, program management, research and development, and treaty enforcement in BosinaHercegovina. 